\title{
Ulrich Haltern
}

\section{Europarecht}

\author{
Dogmatik im Kontext. Band I: Entwicklung - Institutionen - Prozesse
}

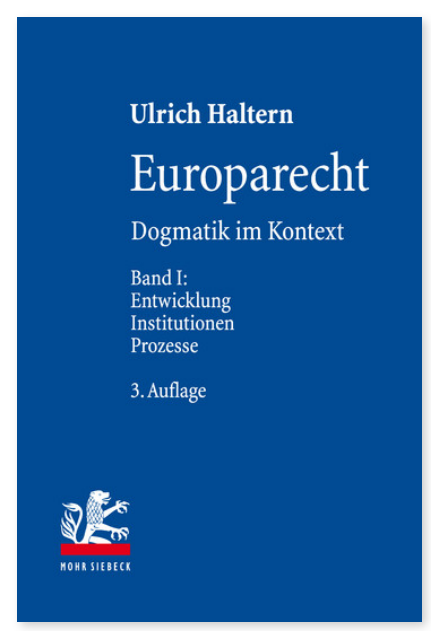

3., völlig überarbeitete und ergänzte Auflage; 2017. XXVIII, 623 Seiten.

ISBN 978-3-16-154590-0

DOI 10.1628/978-3-16-154590-0

eBook PDF $24,00 €$

ISBN 978-3-16-150497-6

fadengeheftete Broschur 24,00€
Das Recht der Europäischen Union ist in ein dynamisches Umfeld eingebettet, das stark durch politische, wirtschaftliche, soziale, kulturelle und institutionelle Kontexte geprägt ist. Diese Einbettung wirkt auf Entstehung, Auslegung und Anwendung des Rechts zurück: Das Verständnis von Unionsrecht hängt an der Rückübersetzung der Kontexte ins Dogmatische. Dieses Lehrbuch will ein solches Verständnis vermitteln, indem es durch eine kontextorientierte juristische Methode die komplexen Zusammenhänge zur Sprache bringt statt sie zu verbergen.

Die vorliegende 3. Auflage geht diesen Weg auf dem aktuellen Stand der Integration weiter. Die ersten zwei Bände behandeln das Verfassungsrecht der Union, wobei Band I sich auf die geschichtliche und juristische Entwicklung der Integration sowie das gesamte Organisationsverfassungsrecht der Union konzentriert. Der noch ausstehende Band III befasst sich mit dem europäischen und internationalen Wirtschaftsrecht.

Die 1. und 2. Auflage sind bei UTB erschienen.

Für Bibliotheken gelten bei diesem Titel abweichende Konditionen; bitte wenden Sie sich an den Vertrieb.

Ulrich Haltern Geboren 1967; Inhaber des Lehrstuhls für Öffentliches Recht, Europarecht und Rechtsphilosophie und Direktor des Munich Center for Law and the Humanities an der LMU München.

\section{Jetzt bestellen:}

https://mohrsiebeck.com/buch/europarecht-9783161545900?no_cache=1

order@mohrsiebeck.com

Telefon: +49 (0)7071-923-17

Telefax: +49 (0)7071-51104 